\title{
The heterogeneous health state profiles of high-risk healthcare utilizers and their longitudinal hospital readmission and mortality patterns
}

Shawn Choon Wee $\mathrm{Ng}^{1+}$, Yu Heng Kwan ${ }^{1,2+}$, Shi Yan', Chuen Seng Tan ${ }^{3}$ and Lian Leng Low ${ }^{4,5,6^{*}}$ (1)

\begin{abstract}
Background: High-risk patients are most vulnerable during transitions of care. Due to the high burden of resource allocation for such patients, we propose that segmentation of this heterogeneous population into distinct subgroups will enable improved healthcare resource planning. In this study, we segmented a high-risk population with the aim to identify and characterize a patient subgroup with the highest 30-day and 90-day hospital readmission and mortality.

Methods: We extracted data from our transitional care program (TCP), a Hospital-to-Home program launched by the Singapore Ministry of Health, from June to November 2018. Latent class analysis (LCA) was used to determine the optimal number and characteristics of latent subgroups, assessed based on model fit and clinical interpretability. Regression analysis was performed to assess the association of class membership on 30- and 90-day all-cause readmission and mortality.

Results: Among 752 patients, a 3-class best fit model was selected: Class 1 "Frail, cognitively impaired and physically dependent", Class 2 "Pre-frail, but largely physically independent" and Class 3 "Physically independent". The 3 classes have distinct demographics, medical and socioeconomic characteristics ( $p<0.05)$, 30- and 90-day readmission $(p<0.05)$ and mortality $(p<0.01)$. Class 1 patients have the highest age-adjusted 90 -day readmission $(\mathrm{OR}=2.04,95 \% \mathrm{Cl}: 1.21-3.46, p=0.008), 30-(\mathrm{OR}=6.92,95 \% \mathrm{Cl}: 1.76-27.21, p=0.006)$ and 90 -day mortality $(\mathrm{OR}=$ $11.51,95 \%$ Cl: $4.57-29.02, p<0.001)$.

Conclusions: We identified a subgroup with the highest readmission and mortality risk amongst high-risk patients. We also found a lack of interventions in our TCP that specifically addresses increased frailty and poor cognition, which are prominent features in this subgroup. These findings will help to inform future program modifications and strengthen existing transitional healthcare structures currently utilized in this patient cohort.
\end{abstract}

Keywords: High-risk healthcare utilizers, Integrated care, Transitional care program, Latent class analysis, Hospital readmissions, Mortality

\footnotetext{
* Correspondence: low.lian.leng@sgh.com.sg

†'Shawn Choon Wee NG and Yu Heng KWAN are co-first authors.

${ }^{4}$ SingHealth Regional Health System, Singapore Health Services, Singapore,

Singapore

${ }^{5}$ Department in Family Medicine and Continuing Care, Population Health

and Integrated Care Office, Singapore General Hospital, 20 College Road,

Singapore 169856, Singapore

Full list of author information is available at the end of the article
}

(c) The Author(s). 2019 Open Access This article is distributed under the terms of the Creative Commons Attribution 4.0 International License (http://creativecommons.org/licenses/by/4.0/), which permits unrestricted use, distribution, and reproduction in any medium, provided you give appropriate credit to the original author(s) and the source, provide a link to the Creative Commons license, and indicate if changes were made. The Creative Commons Public Domain Dedication waiver (http://creativecommons.org/publicdomain/zero/1.0/) applies to the data made available in this article, unless otherwise stated. 


\section{Brief summary}

High-risk healthcare utilizers were segmented into 3 classes, with Class 1 "Frail, cognitively impaired and physically dependent" having the highest 90-day hospital readmission and 30- and 90-day mortality.

\section{Background}

Globally, healthcare systems are facing the challenge of an ageing population with multiple chronic conditions [1]. These patients often experience repeated hospitalizations and are particularly vulnerable during transitions of care, resulting in significant hospital readmissions, mortality and healthcare expenditure $[2,3]$. In Singapore, a multi-ethnic nation of 5.6 million people [4] with one of the most rapidly ageing population in Asia, the 30-day all-cause readmission rates in 2010 was $11.6 \%$ [5], which increased to $19.0 \%$ for patients aged 65 years and older. This is slightly lower than the $19.6 \% 30$ day readmission rate in the United States [6]. Additionally, healthcare expenditure is predicted to exponentially rise from Singapore Dollars (SGD) \$4 billion (USD \$2.98 billion) in 2011 to SGD $\$ 12$ billion (USD \$8.94 billion) in 2020 [7]. In response to this, the Singapore Ministry of Health $(\mathrm{MOH})$ launched the Hospital-to-Home $(\mathrm{H} 2 \mathrm{H})$ program [8], a transitional care program (TCP) that aims to improve the transition from acute care settings back into the community [9]. Likewise, similar programs emphasising population health management have emerged amongst health systems worldwide to understand the determinants of health and deliver solutions to this emerging problem [10].

However, the effectiveness of TCPs in reducing readmission and mortality has so far provided mixed results. Most programs demonstrated an improvement in patient outcomes, but a substantial number showed limited impact or worse outcomes [11-15]. A possible explanation for such inconsistency may be due to different patient subgroups with accompanying risk profiles presenting with varying responses to a standardized TCP intervention. Such a disparity is more critical in complex, high-risk patients with heterogeneous medical and socioeconomic characteristics [3], thereby limiting effectiveness of TCPs if programs do not adequately address this variance. Increasingly, medical complexity alone is found to be insufficient in explaining patterns of post-acute repeat hospitalizations [16]. Socioeconomic risk factors such as religion, health literacy, employment, and quality of family support are also important factors driving health care utilization [17-19].

A promising approach is to segment these heterogeneous populations into relatively homogenous, distinct subgroups with similar characteristics using data. A data-driven approach towards population segmentation has emerged over the years as an attractive methodology, with its ability to utilize large amounts of healthcare dataset to generate evidence-based quantitative insights into a population's health status, thereby informing policy decisions on population health $[10,20]$. To date, data-driven segmentation has not been applied to a high-risk transitional care patient population using both medical and socioeconomic determinants of health to identify specific subgroups of the population with worse outcomes than others. The identification of the highest risk population subgroup (whom often have the poorest health outcome and highest healthcare resource needs) and its associated targetable characteristics would be fundamental towards formulating intervention priorities organized around these characteristics, thereby enabling the delivery of a more effective integrated care at better value $[3,21]$.

In our study, we aim to segment a high-risk patient population in the $\mathrm{H} 2 \mathrm{H}$ program into classes of unique disease profiles and identify a patient subgroup that has the poorest 30- and 90-day hospital readmissions and mortality. In addition, we aim to describe the characteristics representing the disease profile of this segment that may account for their poor health outcomes.

\section{Methods}

\section{Study site, data sources}

Healthcare in Singapore is largely under the responsibility of the Singapore $\mathrm{MOH}$, which uses a mixed financing system that includes nationalized healthcare insurance schemes and deductions from the compulsory savings plan Central Provident Fund (CPF), for Singapore citizens and permanent residents [22, 23]. In 2017, Singapore $\mathrm{MOH}$ launched the $\mathrm{H} 2 \mathrm{H}$ program with the aim of reducing unnecessary hospital admission \& utilizations [9]. It involves inpatient care coordination and community care navigation by nurses through follow-up calls and home visits for high-risk patients with complex chronic disease to ensure care continuity during the transitional period after hospital discharge. These nurses are full-time, degree-holders with an average of 5 years' experience in hospital and/or home care in adults, supervised by masters prepared Advanced Practice Nurses. Hospital readmissions and mortality were obtained at 30- and 90-days after discharge. Duration of intervention typically lasts 6 months.

We used routinely collected clinical data from the $\mathrm{H} 2 \mathrm{H}$ program. Data included demographics (age, gender and race), medical and socioeconomic characteristics. Based on the commonly accepted age to define an older person [24], age was dichotomized into 2 groups, $\leq 65$ years and $>65$ years. We included all $\mathrm{H} 2 \mathrm{H}$ enrolled adult patients (21 years of age and above) who are Singaporean residents or permanent residents. The Singapore General Hospital (SGH) Population Health and Integrated 
Care Office approved the usage of collected data for this study. The Centralized Institutional Review Board (iSHaRe Ref. No. 201707-00005) approved this study for ethics. This study has been published as an abstract for the Society for Academic Primary Care 48th Annual Scientific Meeting conference [25].

\section{Variables used in the latent class analysis}

Multiple variables straddling medical and socioeconomic conditions were reviewed for inclusion. Importantly, these variables were routinely collected in the program as part of patient assessment.

\section{Medical characteristics}

Five variables related to disease state, cognition and functional status were utilised - Charlson Comorbidity Index (CCI), Abbreviated Mental Test (AMT), Clinical Frailty Score (CFS), clinical insight [26] and Activities of Daily Living (ADLs) dependency. Clinical insight was assessed by the nurses on the presence or absence of the patients' understanding of their own medical condition. These variables and their grouped categorical scores have been validated across several countries, including locally as a good discriminative tool for predicting disease status and health outcomes [27-31].

\section{Socioeconomic characteristics}

Four variables - Religion, medicine consolidation issues, quality of family support and employment - were utilized. Religion (or a professed faith) was assessed by the presence or absence of it. Medicine consolidation issues were assessed by the presence or absence of the 5 rights of medication administration: Right patient, drug, dose, route and time [32]. Quality of family support was categorised into 4 groups: absent (patient has no kin), dysfunctional (presence of a high degree of conflict, misbehaviour, neglect and/or abuse occurring continuously and regularly), distant (presence of kin but minimal contact) and supportive. Employment was categorised into 3 groups: unemployed, retired or employed.

\section{Latent class analysis}

LCA is a data-driven method utilizing individual level observable data (indicator variables) to identify underlying latent groups of individuals (classes) [33]. Examples of successful LCA utilization in population segmentation has been demonstrated by Low et al. in the Singapore regional health system [10] and Yan et al. in a primary care population respectively [34]. In this study, 9 identified medical and socioeconomic variables were selected and described above. MPlus Version 8.2 statistical modelling software was used to perform the LCA [35].

The optimal number of classes is determined by the fit statistics and clinical interpretability. Model fit was evaluated using the Bayesian Information Criterion (BIC) and sample-size adjusted BIC (ABIC) [36]. Starting with 1 class, a lower value from BIC or ABIC from each successive model, which has one more class than the prior model, indicates a better fit. Additionally, the estimated probabilities of each indicator variables within each class provide information that describes the classes and determines whether the classes are distinct from one another and clinically interpretable. Separate LCA models were generated successively from 1 through 4 class solutions. From the LCA that corresponded to the optimal number of classes identified, the posterior probability of membership for each class is computed for each subject which is assigned to the class with the maximum posterior probability.

\section{Statistical analysis}

Firstly, to examine whether significant differences between demographics and disease patterns exist across the classes, we used Fisher exact test for the categorical variables. Next, we identified potentially confounding factors through a univariate analysis of demographics against class and health outcomes. Lastly, to assess the association of class membership on hospital readmissions and mortality, we used logistic regression with Class 3 as reference. The models were adjusted for age. Analyses were performed using SAS, version 0.4 (SAS Institute, Inc., Cary, NC).

\section{Results}

\section{Segmentation outcome}

A final LCA model of 3 classes was identified based on its better statistical fit (lowest BIC and ABIC) and clinical interpretability (Additional file 1: Table S1). 752 patients enrolled from June to November 2018 were segmented into 3 classes and labelled based on the estimated probability of each indicator variable within each class: Class 1 "Frail, cognitively impaired, physically dependent"; Class 2 "Pre-frail but largely physically independent"; and Class 3 "Physically independent". A summary of the overall prevalence of the 9 indicator variables and the percentage of individuals in each class for each variable is provided in Table 1.

The 3 classes displayed significantly different medical and socioeconomic characteristics (Table 1). Overall, Class 1 fared the worst in these variables: unemployment (92.2\%), ADLs dependent (44.7\%), poor cognition (76.7\% with AMT 0-6), moderately frail (91.3\% with CFS 6-8 points) and significant comorbidity $(94.2 \%$ with $\mathrm{CCI} \geq 3)$.

\section{Demographics}

As shown in Table 1, 68\% of the study population were > 65 years old. Subjects in Class 1 were the oldest $(90.3 \%$ aged $>65$ years old) and those in Class 3 were the youngest $(45.1 \%$ aged $>65$ years old) among the three classes. 
Table 1 Demographics, indicator variables and health outcomes by class $(N=752)$

\begin{tabular}{|c|c|c|c|c|c|}
\hline & $\begin{array}{l}\text { Total } \\
(N=752)\end{array}$ & $\begin{array}{l}\text { Class 1: Frail, cognitively impaired, physically } \\
\text { dependent }(N=103,13.7 \%)\end{array}$ & $\begin{array}{l}\text { Class 2: Pre-frail but largely physically in- } \\
\text { dependent }(N=323,43 \%)\end{array}$ & $\begin{array}{l}\text { Class 3: Physically } \\
\text { independent }(N=326,43.3 \%)\end{array}$ & $P$-value \\
\hline \multicolumn{6}{|l|}{ Demographics } \\
\hline Age (year) & & & & & $<0.001$ \\
\hline$>65$ years & $511(68)$ & $93(90.3)$ & $271(83.9)$ & $147(45.1)$ & \\
\hline$\leq 65$ years & 241 (32) & $10(9.7)$ & $52(16.1)$ & $179(54.9)$ & \\
\hline Range & 20,98 & 30,98 & 35,97 & 20,95 & \\
\hline Gender, n (\%) & & & & & 0.018 \\
\hline Female & $\begin{array}{l}394 \\
(52.4)\end{array}$ & $66(64.1)$ & $171(52.9)$ & $157(48.2)$ & \\
\hline Male & $\begin{array}{l}358 \\
(47.6)\end{array}$ & $37(35.9)$ & $152(47.1)$ & $169(51.8)$ & \\
\hline Race, n (\%) & & & & & 0.039 \\
\hline Chinese & $\begin{array}{l}588 \\
(78.2)\end{array}$ & $78(75.7)$ & $268(83.0)$ & $242(74.2)$ & \\
\hline Indian & $69(9.2)$ & $10(9.7)$ & $28(8.7)$ & $31(9.5)$ & \\
\hline Malay & $77(10.2)$ & $10(9.7)$ & $24(7.4)$ & $43(13.2)$ & \\
\hline Others & $18(2.4)$ & $5(4.9)$ & $3(0.9)$ & $10(3.1)$ & \\
\hline \multicolumn{6}{|l|}{ Indicator variables } \\
\hline Religion, n (\%) & & & & & $<0.001$ \\
\hline No & $\begin{array}{l}234 \\
(31.1)\end{array}$ & $31(30.1)$ & $76(23.5)$ & $127(39.0)$ & \\
\hline Yes & $\begin{array}{l}518 \\
(68.9)\end{array}$ & $72(69.9)$ & 247 (76.5) & $199(61.0)$ & \\
\hline $\begin{array}{l}\text { Medicine } \\
\text { consolidation issues, } \\
\mathrm{n}(\%)\end{array}$ & & & & & 0.006 \\
\hline No & $\begin{array}{l}673 \\
(89.5)\end{array}$ & 89 (86.4) & $279(86.4)$ & 305 (93.6) & \\
\hline Yes & 79 (10.5) & $14(13.6)$ & $44(13.6)$ & $21(6.4)$ & \\
\hline $\begin{array}{l}\text { Quality of family } \\
\text { support, } \mathrm{n}(\%)\end{array}$ & & & & & $<0.001$ \\
\hline Absent & $48(6.4)$ & $2(1.9)$ & $11(3.4)$ & $35(10.7)$ & \\
\hline Dysfunctional & $11(1.5)$ & $1(1.0)$ & $9(2.8)$ & $1(0.3)$ & \\
\hline Distant & $35(4.7)$ & $2(1.9)$ & $18(5.6)$ & $15(4.6)$ & \\
\hline Supportive & $\begin{array}{l}658 \\
(87.5)\end{array}$ & $98(95.1)$ & $285(88.2)$ & $275(84.4)$ & \\
\hline Employment, n (\%) & & & & & $<0.001$ \\
\hline Unemployed & $\begin{array}{l}537 \\
(71.4)\end{array}$ & $95(92.2)$ & $307(95.0)$ & $135(41.4)$ & \\
\hline Retired & $30(4.0)$ & $5(4.9)$ & $9(2.8)$ & $16(4.9)$ & \\
\hline Employed & $\begin{array}{l}185 \\
(24.6)\end{array}$ & $3(2.9)$ & $7(2.2)$ & $175(53.7)$ & \\
\hline Clinical insight, n (\%) & & & & & 0.003 \\
\hline No & $45(6.0)$ & $5(4.9)$ & $30(9.3)$ & $10(3.1)$ & \\
\hline Yes & $\begin{array}{l}707 \\
(94.0)\end{array}$ & $98(95.1)$ & $293(90.7)$ & $316(96.9)$ & \\
\hline ADL, n (\%) & & & & & $<0.001$ \\
\hline Dependent & $46(6.1)$ & $46(44.7)$ & 0 & 0 & \\
\hline Moderate Assist & $56(7.4)$ & $46(44.7)$ & $10(3.1)$ & 0 & \\
\hline Minimal Assist & $\begin{array}{l}121 \\
(16.1)\end{array}$ & $11(10.7)$ & $108(33.4)$ & $2(0.6)$ & \\
\hline Independent & $\begin{array}{l}529 \\
(70.3)\end{array}$ & 000 & $205(63.5)$ & 324 (99.4) & \\
\hline AMT, n (\%) & & & & & $<0.001$ \\
\hline
\end{tabular}


Table 1 Demographics, indicator variables and health outcomes by class $(N=752)$ (Continued)

\begin{tabular}{|c|c|c|c|c|c|}
\hline & $\begin{array}{l}\text { Total } \\
(N=752)\end{array}$ & $\begin{array}{l}\text { Class 1: Frail, cognitively impaired, physically } \\
\text { dependent }(N=103,13.7 \%)\end{array}$ & $\begin{array}{l}\text { Class 2: Pre-frail but largely physically in- } \\
\text { dependent }(N=323,43 \%)\end{array}$ & $\begin{array}{l}\text { Class 3: Physically } \\
\text { independent }(N=326,43.3 \%)\end{array}$ & $P$-value \\
\hline 0-6 point(s) & $\begin{array}{l}136 \\
(18.1)\end{array}$ & $79(76.7)$ & $52(16.1)$ & $5(1.5)$ & \\
\hline $7-10$ points & $\begin{array}{l}616 \\
(81.9)\end{array}$ & $24(23.3)$ & $271(83.9)$ & $321(98.5)$ & \\
\hline CFS, n (\%) & & & & & $<0.001$ \\
\hline 1-3 point(s) & $\begin{array}{l}322 \\
(42.8)\end{array}$ & 0 & $27(8.4)$ & $295(90.5)$ & \\
\hline $4-5$ points & $\begin{array}{l}292 \\
(38.8)\end{array}$ & $9(8.7)$ & $253(78.3)$ & $30(9.2)$ & \\
\hline $6-8$ points & $\begin{array}{l}138 \\
(18.4)\end{array}$ & $94(91.3)$ & $43(13.3)$ & $1(0.3)$ & \\
\hline CCl score, n (\%) & & & & & $<0.001$ \\
\hline 0 points & $39(5.2)$ & $2(1.9)$ & 0 & $37(11.3)$ & \\
\hline 1 point & $53(7.0)$ & $3(2.9)$ & 0 & $50(15.3)$ & \\
\hline 2 points & $63(8.4)$ & $1(1.0)$ & $10(3.1)$ & $52(16.0)$ & \\
\hline$\geq 3$ points & $\begin{array}{l}597 \\
(79.4)\end{array}$ & $97(94.2)$ & $313(96.9)$ & $187(57.4)$ & \\
\hline \multicolumn{6}{|l|}{ Health outcomes } \\
\hline \multicolumn{6}{|c|}{ Hospital readmission n (\%) } \\
\hline 30 days & $\begin{array}{l}112 \\
(14.9)\end{array}$ & $18(17.5)$ & $59(18.3)$ & $35(10.7)$ & 0.027 \\
\hline 90 days & $\begin{array}{l}182 \\
(24.2)\end{array}$ & $35(34.0)$ & $86(26.6)$ & $61(18.7)$ & 0.004 \\
\hline \multicolumn{6}{|l|}{ Mortality, n (\%) } \\
\hline 30 days & $22(2.9)$ & $7(6.8)$ & $12(3.7)$ & $3(0.9)$ & 0.005 \\
\hline 90 days & $56(7.4)$ & $22(21.4)$ & $27(8.4)$ & $7(2.1)$ & $<0.001$ \\
\hline
\end{tabular}

The majority of the study population were Chinese, paralleling the general Singapore population [37]. The differences in age, gender and race were statistically significant $(p<0.05)$.

\section{Hospital readmissions and mortality patterns}

Table 1 shows the hospital readmissions and mortality patterns at 30 and 90 days after discharge across the 3 classes. Class 1 had the highest 90-day hospital readmission $(p=0.004)$ and 30 - and 90-day mortality $(p=0.005$ and $<0.001$ respectively).

In Table 2, the segmented classes persisted to be significantly associated with 90-day hospital readmission, and 30- and 90-day mortality after adjustment for age. Class 1 had the highest odds for 90-day readmission $(\mathrm{OR}=2.04$, 95\% CI: $1.21-3.46, p$-value $=0.008), 30$-day mortality $(\mathrm{OR}=6.92,95 \%$ CI: $1.76-27.21, p$-value $=0.006)$ and 90 day mortality $(\mathrm{OR}=11.51,95 \% \mathrm{CI}: 4.57-29.02, p$-value $<$ 0.001 ) among the 3 classes. Though not as high as Class 1 , Class 2 also had higher odds for 90-day readmission (OR = $1.43,95 \%$ CI: $0.96-2.14, p$-value $=0.079), 30$-day mortality $(\mathrm{OR}=3.56,95 \% \mathrm{CI}: 1.02-12.43, p$-value $=0.046)$ and 90 day mortality $(\mathrm{OR}=3.84,95 \% \mathrm{CI}$ : $1.61-9.12, p$-value $=$ 0.002) when compared to Class 3.

\section{Discussion}

Utilizing LCA, this study segmented the heterogeneous health profiles of $\mathrm{H} 2 \mathrm{H}$ patients into 3 classes with 
Table 2 Univariate and multivariate analysis on hospital readmissions and mortality

\begin{tabular}{|c|c|c|c|c|}
\hline & Unadjusted OR (95\% CI) & $p$-value & Adjusted $\mathrm{OR}^{\mathrm{a}}(95 \% \mathrm{Cl})$ & $p$-value \\
\hline Hospital readmissions at 30 days & & $0.029^{*}$ & & $0.103^{*}$ \\
\hline Class 1: Frail, cognitively impaired and physically dependent & $1.75(0.95,3.23)$ & 0.075 & $1.61(0.84,3.08)$ & 0.153 \\
\hline Class 2: Pre-frail, but largely physically independent & $1.80(1.15,2.81)$ & 0.011 & $1.67(1.03,2.71)$ & 0.037 \\
\hline Class 3: Physically independent & Reference & & & \\
\hline Hospital readmissions at 90 days & & $0.005^{*}$ & & $0.025^{*}$ \\
\hline Class 1: Frail, cognitively impaired and physically dependent & $2.20(1.34,3.61)$ & 0.002 & $2.04(1.21,3.46)$ & 0.008 \\
\hline Class 2: Pre-frail, but largely physically independent & $1.53(1.05,2.21)$ & 0.026 & $1.43(0.96,2.14)$ & 0.079 \\
\hline Class 3: Physically independent & Reference & & & \\
\hline Mortality at 30 days & & $0.012^{*}$ & & $0.021^{*}$ \\
\hline Class 1: Frail, cognitively impaired and physically dependent & $7.06(1.94,25.71)$ & 0.003 & $6.92(1.76,27.21)$ & 0.006 \\
\hline Class 2: Pre-frail, but largely physically independent & $3.61(1.09,11.94)$ & 0.036 & $3.56(1.02,12.43)$ & 0.046 \\
\hline Class 3: Physically independent & Reference & & & \\
\hline Mortality at 90 days & & $<0.001^{*}$ & & $<0.001^{*}$ \\
\hline Class 1: Frail, cognitively impaired and physically dependent & $11.57(4.88,27.46)$ & $<.001$ & $11.51(4.57,29.02)$ & $<0.001$ \\
\hline Class 2: Pre-frail, but largely physically independent & $3.84(1.68,8.76)$ & 0.001 & $3.84(1.61,9.12)$ & 0.002 \\
\hline Class 3: Physically independent & Reference & & & \\
\hline
\end{tabular}

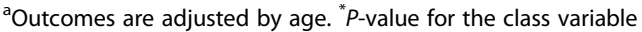

distinct medical, social and demographic patterns. We further showed the different health outcomes between the 3 classes, demonstrating the utility of population segmentation in prognosticating patients and highlighting cohorts of patients that require differing tiers of care. Such an understanding would be fundamental for health policymakers and clinicians to make informed decisions on targeted health interventions for each class, allowing for optimal resource allocation and better health outcomes in a resource-strapped environment.

Class 1 "Frail, cognitively impaired, physically dependent" is prominent with the highest 90-day readmission and 30- and 90-day mortality amongst the three classes.. These highlights important areas of intervention for this high risk class in the existing $\mathrm{H} 2 \mathrm{H}$ program, namely interventions targeting frailty and cognition. Our findings are congruent with existing literature, where patients who are frail and/or have poor cognition have poorer health outcome and increased healthcare utilization [38, 39]. In addition, the lack of specific clinical pathways addressing cognition is also echoed by previously conducted systematic reviews on TCPs and its components globally [40, 41], highlighting the need for the development of more robust interventions in TCPs targeting these deficits.

In terms of frailty, multicomponent interventions spanning multiple domains such as physical exercise programs (such as Tai Chi and resistance training), cognitive training, and provision of nutritional supplements have been found to be consistently successful and may be incorporated in TCPs as deemed appropriate [42].
With regards to cognition, specifically dementia, nonpharmacological interventions that are low-cost and safe such as cognitive stimulation therapy and reality orientation have been found to be correlated with cognitive and behavioural benefits [43]. Additionally, given that caregiver burden factors in as a major component affecting dementia patients' outcome, adequate interventions such as caregiver training and education, and peripheral supportive infrastructures are necessary to address this deficit [44]. A Alternatively, given the high mortality rate for Class 1, palliative care may be a viable option to provide for end-of-life needs; seeking to improve quality of life and potentially reduce healthcare utilisation [45], especially when the extension of life may be futile or at the expanse of patients' overall well-being. Indicators such as Advance Care Planning and appropriate place of death may provide insights into a TCP's effectiveness, in addition to metrics such as readmission and mortality rate.

This study had several limitations. Firstly, the unique socioeconomic characteristics of our patient population in a multi-ethnic nation Singapore meant its generalizability to other patient populations may be limited. However, given that the bulk of the class differences lie in medical factors, this limitation would be limited. Secondly, the indicators used for segmentation were routinely collected medical and socioeconomic variables, which may not capture all health determinants. Future research may expand routinely collected data to variables showing a major influence on health outcomes, such as mental health and substance abuse [16]. Thirdly, 
the small Class 1 sample size $(N=103)$ may have contributed to the lack of significance for Class 1 30-day readmission. Future research needs to be done with larger sample sizes to elicit the significance or lack thereof between class and 30-day readmission rates. Lastly, the association between class and health outcomes were not adjusted by gender and race. Although both gender and race were significantly associated with the class (exposure), they demonstrated poor association with readmissions and mortality (outcomes) (Additional file 1: Table S2). Hence, they were not regarded as true confounding factors to be adjusted for [46].

\section{Conclusions}

We identified a high-risk patient population subgroup in the $\mathrm{H} 2 \mathrm{H}$ program that is frail, cognitively impaired and physically dependent and has the highest overall hospital readmission and mortality risk. Interventions targeting frailty and poor cognition may be useful in this patient segment to improve health outcomes. Segmentation using medical and socioeconomic factors may be replicated by other health systems, forming the foundation for population-level health resource planning and tailored transitional care interventions.

\section{Supplementary information}

Supplementary information accompanies this paper at https://doi.org/10. 1186/s12913-019-4769-7.

Additional file 1: Table S1. Criteria to assess model fit for latent class analysis models. Table S2. Univariate analysis of demographics on health outcomes.

\section{Abbreviations}

H2H: Hospital-to-home; LCA: Latent class analysis; TCP: Transitional care program

\section{Acknowledgements}

The authors would like to thank the community nurses involved in the Hospital-to-Home $(\mathrm{H} 2 \mathrm{H})$ program of the Singapore General Hospital for supporting this study.

\section{Authors' contributions}

SCW was involved in the study conception, design, data collection, data analysis and drafted the manuscript. YH was involved in the data analysis and the review of the manuscript. SY was involved in the review of the manuscript. CS was involved in the statistical analysis and review of the manuscript. LL was involved in the study conception, design, data analysis and review of the manuscript. All authors read and approved the final manuscript.

\section{Funding}

There is no funding provided to produce this manuscript.

\section{Availability of data and materials}

The relevant anonymized datasets used and/or analysed during the current study are available from the corresponding author on reasonable request.

\section{Ethics approval and consent to participate}

This Singapore SingHealth Centralized Institutional Review Board issued the ethical approval for this study (Ref No. 201707-00005). Waiver of informed consent has been requested for all study subject on the grounds of data being collected as part of patients' routine care, and information collected not affecting clinical decisions nor deprive any individual's entitled care. Furthermore, all the collected data would be de-identified. The SGH Population Health and Integrated Care Office approved the usage of collected data for this study.

\section{Consent for publication}

Not applicable.

\section{Competing interests}

Dr. Low Lian Leng is a member of the editorial board (Associate Editor) for BMC HSR. The remaining authors declare that they have no competing interests.

\section{Author details}

${ }^{1}$ Duke-NUS Medical School, Singapore, Singapore. ${ }^{2}$ Program in Health Services and Systems Research, Duke-NUS Medical School, Singapore, Singapore. ${ }^{3}$ Saw Swee Hock School of Public Health, National University of Singapore, Singapore, Singapore. ${ }^{4}$ SingHealth Regional Health System, Singapore Health Services, Singapore, Singapore. ${ }^{5}$ Department in Family Medicine and Continuing Care, Population Health and Integrated Care Office, Singapore General Hospital, 20 College Road, Singapore 169856, Singapore.

${ }^{6}$ Singhealth Duke-NUS Family Medicine Academic Clinical Program,

Singapore, Singapore.

Received: 19 July 2019 Accepted: 22 November 2019

Published online: 04 December 2019

\section{References}

1. Bauer UE, Briss PA, Goodman RA, Bowman BA. Prevention of chronic disease in the 21st century: elimination of the leading preventable causes of premature death and disability in the USA. Lancet. 2014;384(9937):45-52.

2. Naylor M, Keating SA. Transitional care: moving patients from one care setting to another. Am J Nurs. 2008;108(9 Suppl):58-63.

3. Suzman R, Beard JR, Boerma T, Chatterii S. Health in an ageing world--what do we know? Lancet. 2015;385(9967):484-6.

4. Low LL, Wah W, Ng MJ, Tan SY, Liu N, Lee KH. Housing as a social determinant of health in Singapore and its association with readmission risk and increased utilization of hospital services. Front Public Health. 2016;4:109.

5. Lim E, Matthew N, Mok W, Chowdhury S, Lee D. Using hospital readmission rates to track the quality of care in public hospitals in Singapore. BMC Health Serv Res. 2011;11(Suppl 1):A16-A.

6. Jencks SF, Williams MV, Coleman EA. Rehospitalizations among patients in the medicare fee-for-service program. N Engl J Med. 2009;360(14):1418-28.

7. Aziz I. Healthcare spending to hit $\$ \$ 12$ billion by 2020: Tharman. TODAY Newspaper; 2014

8. Low LL, Vasanwala FF, Ng LB, Chen C, Lee KH, Tan SY. Effectiveness of a transitional home care program in reducing acute hospital utilization: a quasi-experimental study. BMC Health Serv Res. 2015;15:100.

9. Choo F. Hospital-to-Home programme has helped around 8,000 patients. The Straits Time 20182 February 2018.

10. Low LL, Yan S, Kwan YH, Tan CS, Thumboo J. Assessing the validity of a data driven segmentation approach: a 4 year longitudinal study of healthcare utilization and mortality. PLoS One. 2018;13(4):e0195243.

11. Allen J, Hutchinson AM, Brown R, Livingston PM. Quality care outcomes following transitional care interventions for older people from hospital to home: a systematic review. BMC Health Serv Res. 2014;14:346.

12. Kamermayer AK, Leasure AR, Anderson L. The effectiveness of transitions-ofcare interventions in reducing hospital readmissions and mortality: a systematic review. Dimens Crit Care Nurs. 2017;36(6):311-6.

13. Lee $\mathrm{KH}$, Low LL, Allen J, Barbier S, Ng LB, Ng MJ, et al. Transitional care for the highest risk patients: findings of a randomised control study. Int J Integr Care. 2015;15:e039.

14. Low LL, Tan SY, Ng MJ, Tay WY, Ng LB, Balasubramaniam K, et al. Applying the integrated practice unit concept to a modified virtual Ward model of Care for Patients at highest risk of readmission: a randomized controlled trial. PLoS One. 2017;12(1):e0168757.

15. Low LL, Tay WY, Tan SY, Chia EHS, Towle RM, Lee KH. Transitional home care program utilizing the integrated practice unit concept (THC-IPU): effectiveness in improving acute hospital utilization. Int J Integr Care. 2017; 17(4):5 
16. Rinehart DJ, Oronce C, Durfee MJ, Ranby KW, Batal HA, Hanratty R, et al. Identifying subgroups of adult Superutilizers in an urban safety-net system using latent class analysis: implications for clinical practice. Med Care. 2018; 56(1):e1-9.

17. Kersting RC. Impact of social support, diversity, and poverty on nursing home utilization in a nationally representative sample of older Americans. Soc Work Health Care. 2001;33(2):67-87.

18. Hong CS, Siegel AL, Ferris TG. Caring for high-need, high-cost patients: what makes for a successful care management program? Issue Brief (Commonw Fund). 2014;19:1-19.

19. Schiller PL, Levin JS. Is there a religious factor in health care utilization?: a review. Soc Sci Med. 1988;27(12):1369-79.

20. Yan S, Kwan YH, Tan CS, Thumboo J, Low LL. A systematic review of the clinical application of data-driven population segmentation analysis. BMC Med Res Methodol. 2018;18(1):121.

21. Porter ME. What is value in health care? N Engl J Med. 2010;363(26):2477-81.

22. Costs and Financing. Available from: https://www.moh.gov.sg/content/ moh_web/home/costs_and_financing.html. Accessed 25 Sept 2019.

23. Chan $\mathrm{CQH}$, Lee $\mathrm{KH}$, Low LL. A systematic review of health status, health seeking behaviour and healthcare utilisation of low socioeconomic status populations in urban Singapore. Int J Equity Health. 2018;17(1):39.

24. WHO GS. Proposed working definition of an older person in Africa for the MDS project; 2002

25. Ng SCW, Kwan YH, Low LL. The heterogeneous health state profiles of highrisk healthcare utilizers and their longitudinal healthcare service utilization and mortality patterns. Society for Academic Primary Care 48th Annual Scientific Meeting Exeter, England 2019.

26. Amador XF, David AS. Insight and psychosis. New York: Oxford University Press; 1998.

27. Tan SY, Low LL, Yang Y, Lee KH. Applicability of a previously validated readmission predictive index in medical patients in Singapore: a retrospective study. BMC Health Serv Res. 2013;13(1):366.

28. Deyo RA, Cherkin DC, Ciol MA. Adapting a clinical comorbidity index for use with ICD-9-CM administrative databases. J Clin Epidemiol. 1992;45(6):613-9.

29. Gregorevic KJ, Hubbard RE, Lim WK, Katz B. The clinical frailty scale predicts functional decline and mortality when used by junior medical staff: a prospective cohort study. BMC Geriatr. 2016;16:117

30. Antonelli Incalzi R, Cesari M, Pedone C, Carosella L, Carbonin PU. Gruppo Italiano di Farmacovigilanza nA. Construct validity of the abbreviated mental test in older medical inpatients. Dement Geriatr Cogn Disord. 2003;15(4):199-206.

31. Nakajima H, Yoshioka J, Totsuka N, Miyazawa I, Usui T, Urasawa N, et al. Activities of daily living as an additional predictor of complications and outcomes in elderly patients with acute myocardial infarction. Clin Interv Aging. 2016;11:1141-7.

32. Hughes RG, Blegen MA. Patient Safety and Quality: An Evidence-Based Handbook for Nurses. Advances in Patient Safety. In: Hughes RG, editor. Medication Administration Safety. Rockville: Agency for Healthcare Research and Quality (AHRQ); 2008.

33. Hagenaars JA, AL MC. Applied Latent Class Analysis. Cambridge: University Press; 2009.

34. Yan S, Seng BJJ, Kwan YH, Tan CS, Quah JHM, Thumboo J, et al. Identifying heterogeneous health profiles of primary care utilizers and their differential healthcare utilization and mortality - a retrospective cohort study. BMC Fam Pract. 2019;20(1):54.

35. Muthe'n LK, Muthe'n BO. Mplus User's Guide, 6th ed. Los Angeles: Muthe'n \& Muthe'n; 1998-2010.

36. Sclove SL. Application of model-selection criteria to some problems in multivariate analysis. Psychometrika. 1987;52(3):333-43.

37. Statistics SDo. Population trends Department of Statistics. 2018.

38. Kojima G, Liljas AEM, Iliffe S. Frailty syndrome: implications and challenges for health care policy. Risk Manag Healthc Policy. 2019;12:23-30.

39. Kallenberg MH, Kleinveld HA, Dekker FW, van Munster BC, Rabelink TJ, van Buren $\mathrm{M}$, et al. Functional and cognitive impairment, frailty, and adverse health outcomes in older patients reaching ESRD-A systematic review. Clin J Am Soc Nephrol. 2016;11(9):1624-39.

40. Kansagara D, Chiovaro JC, Kagen D, Jencks S, Rhyne K, O'Neil M, et al. Transitions of care from hospital to home: an overview of systematic reviews and recommendations for improving transitional Care in the Veterans Health Administration. VA Evidence-based Synthesis Program Reports. Washington (DC) 2015
41. Viggiano T, Pincus HA, Crystal S. Care transition interventions in mental health. Curr Opin Psychiatry. 2012;25(6):551-8.

42. Apostolo J, Cooke R, Bobrowicz-Campos E, Santana S, Marcucci M, Cano A, et al. Effectiveness of interventions to prevent pre-frailty and frailty progression in older adults: a systematic review. JBI Database System Rev Implement Rep. 2018;16(1):140-232.

43. Berg-Weger M, Stewart DB. Non-pharmacologic interventions for persons with dementia. Mo Med. 2017;114(2):116-9.

44. Hirschman KB, Hodgson NA. Evidence-based interventions for transitions in care for individuals living with dementia. Gerontologist. 2018;58(suppl_1): S129-S40.

45. Anagnostou D. Palliative care improves quality of life and reduces symptom burden in adults with life-limiting illness. Evid Based Nurs. 2017;20(2):47-8.

46. Skelly AC, Dettori JR, Brodt ED. Assessing bias: the importance of considering confounding. Evid Based Spine Care J. 2012;3(1):9-12.

\section{Publisher's Note}

Springer Nature remains neutral with regard to jurisdictional claims in published maps and institutional affiliations.

Ready to submit your research? Choose BMC and benefit from:

- fast, convenient online submission

- thorough peer review by experienced researchers in your field

- rapid publication on acceptance

- support for research data, including large and complex data types

- gold Open Access which fosters wider collaboration and increased citations

- maximum visibility for your research: over $100 \mathrm{M}$ website views per year

At BMC, research is always in progress.

Learn more biomedcentral.com/submissions 